\title{
Artigos
}

Fernanda Theodoro Roveri'

Carmen Lúcia Soares ${ }^{2}$

\section{Compre, colecione e fique na moda: reflexões sobre o consumismo infantil e o brincar}

Resumo: Os brinquedos e outros artigos de consumo são dirigidos às crianças de modo a lhes sugerirem desejos de posse, distinção e pertencimento social. As propagandas costumam condicionar comportamentos ao estilo do produto, fazendo com que meninas e meninos permaneçam defrontes a um universo midiático coordenado por ídolos e estrelas da moda. Estes, ao veicularem mercadorias e estilos de vida, trazem indicativos de feminilidade e de masculinidade. Este artigo elege a boneca Barbie para uma discussão sobre a infância, procurando refletir sobre os padrões de comportamento e de corpo ensinados às crianças. Busca-se, pois, discutir os ideais de consumo, beleza, feminilidade e prazer apresentados por esta boneca, um dos ícones da infância de garotas do mundo todo.

Palavras-chave: infância; consumismo; brinquedo; boneca Barbie.

\section{Buy, collect and stay fashionable: reflections on child consumption and the play}

Abstract: Toys and other consumption articles are offered to children with the objective of suggesting desires of possession, distinction and social belonging to them. Advertising tries to condition behaviors to the style of the product, causing boys and girls to face a mediatic universe ruled by idols and fashion stars. These, in turn, bring indications of femininity and masculinity when they transmit life styles and goods. This article chooses Barbie doll for a discussion about childhood trying to reflect about behavior and body patterns taught to children. The target is then to discuss ideals of consumption, femininity and pleasure introduced by that doll, one of the childhood icons of girls from all around the world.

Keywords: childhood, consumption, toys, Barbie doll 
s brinquedos, ao prometerem o prazer e a diversão, costumam ser vistos como partes do reino da fantasia e da imaginação infantil. No entanto, considerando que são objetos fabricados pelos adultos e que fazem parte de um processo de produção industrial, descortinamos esse reinado da pureza revelando sua produção em fábricas instaladas em países onde o custo de mão de obra é mais baixo e nas quais os trabalhadores encontram-se desprovidos de direitos sindicais muitos ficam expostos às substâncias tóxicas usadas para a fabricação da maior parte dos brinquedos ${ }^{3}$ (KLEIN, 2006; OLIVEIRA, 1986). É importante, nesse sentido, destacarmos que os brinquedos não são objetos de pureza, inocência e encantamento, mas são bens de consumo cujos fabricantes competem pela conquista da infância. Para Benjamin (2002), é impossível construir o brinquedo no âmbito da fantasia ou da inocência:

\footnotetext{
O brinquedo, mesmo quando não imita os instrumentos dos adultos, é confronto, e, na verdade, não tanto da criança com os adultos, mas destes com a criança. Pois quem senão o adulto fornece primeiramente à criança os seus brinquedos? E embora reste a ela certa liberdade em aceitar ou recusar as coisas, não poucos dos mais antigos brinquedos (bola, arco, roda de penas, pipa) terão sido de certa forma impostos à criança como objetos de culto, os quais só mais tarde, e certamente graças à força da imaginação infantil, transformaram-se em brinquedos (BENJAMIN, 2002, p. 96).
}

É importante considerarmos também que os brinquedos são vendidos de forma segmentada para as meninas e para os meninos, ditando algumas formas de como estes devem olhar para si mesmos e para os outros. $\mathrm{Na}$ sociedade contemporânea a figura do indivíduo perde a força para a de consumidor, sendo este estimulado a comprar "modos de ser" (SIBILIA, 2002). Os brinquedos, neste processo, são direcionados às crianças-consumidoras e continuamente apresentam-lhes estilos e comportamentos desejáveis.

Um olhar atento para a infância e para a instituição escolar significa a percepção dos

3 De acordo com relatório de 2013 da Associação Brasileira dos Fabricantes de Brinquedos (Abrinq), os países que lideraram as importações de brinquedos no Brasil em 2012 foram China (83,2\%), Indonésia (4,9\%) e Malásia (3,3\%). Disponível em:

$<$ http://mww.abrinq.com.br/download/A_forca_do_brinquedo_Estatisticas_20/3.pdf >. Acesso em: 20 fev. 2014 
mecanismos de poder que, sob a forma de entretenimento, lançam a promessa da felicidade, da diversão e do prazer. Depois que os fabricantes descobriram, na década de 1950, que poderiam dialogar diretamente com a criança, fazendo dela um consumidor em potencial, inúmeras empresas começaram a competir pela atenção do público infantil, criando propagandas sedutoras para incitar o desejo de compra (STEINBERG e KINCHELOE, 2001).

Hoje as opções de brinquedos são muitas e o mercado virtual também disputa a atenção do público infantil. Percebemos que na maioria das vezes é a própria criança quem determina os produtos a serem comprados pelos adultos e grande parte desfruta de raros momentos de interações, trocas e experiências diversificadas que permitiriam uma reelaboração dos sentidos atribuídos aos produtos consumidos. Atentos a esta característica, os fabricantes de brinquedos investem na veiculação de produtos eletrônicos que provocam emoções instantâneas, preenchem o tempo das crianças e lhes prometem fazer companhia. Conforme revelou o diretor de marketing da fabricante de brinquedos Estrela,

\begin{abstract}
A grande menina dos olhos da indústria é a eletrônica. Hoje a criança detém muita informação e é uma criança solitária, porque a média de filhos por mulher é I,8, ou seja, a criança não tem mais a companhia do irmão para brincar. Então os brinquedos precisam ter cada vez mais interatividade, porque precisam convidar a criança para brincar com eles ${ }^{4}$.
\end{abstract}

Associar os brinquedos ao nome de um personagem também se tornou uma prática comum no mercado e tem como propósito diluir os custos de produção criando uma linha de artigos que se beneficia dos sucessos e lançamentos veiculados nas mídias. No Brasil, os produtos licenciados que materializam as figuras de cinema geraram, em 2013, um faturamento em torno de R \$12,4 bilhões ${ }^{5}$. Para os empresários de brinquedos, uma das vantagens de vender produtos licenciados é que qualquer publicidade realizada no lançamento de um filme acaba favorecendo imediatamente o setor que adquiriu a licença.

Dentre o seguimento de bonecas, Barbie se destaca por ter ultrapassado os limites do objeto material - uma boneca personificada - e atingido o conceito de uma marca. O argumento é ser a "melhor amiga" da menina e poder fazer-se presente ao seu lado o dia todo, como se disputasse o espaço íntimo da criança. Sua imagem é evocada na hora das refeições (pratos, copos personalizados), na festa de aniversário (convites, pratinhos, enfeites, toalha de mesa), na higiene pessoal (xampus, sabonetes, perfumes), e no momento do sono (colcha, travesseiro, lençol), por

\footnotetext{
4 A entrevista publicada em 24/04/20/3 no site Terra: "Fabricantes de brinquedos investem em tablets e volta de clássicos em 2013" foi realizada na ocasião da $30^{a}$ Abrin Feira Brasileira de Brinquedos. Disponível em: <http:l/economia terra com brlfabricantes-de-brinquedos-investem-em-tablets-e-volta-de-classicos-em2013,81/82/c2098904 IOVgnCLD200000bbcceb0aRCRD.html> Acesso em 20 fev. 2014

5 Segundo cálculos da Associação Brasileira de Licenciamento (ABRAL). Disponível em: < http://abral.org.br/vendas-de-produtos-licenciados-atingem-r-12480-bilhoes/>. Acesso em: 27/02/20/4.
} 
exemplo. Seu brilho de estrela-guia captura a criança, a encanta, chamando-a para viver uma experiência "feliz e inesquecível". À criança é dada a oportunidade de um prazer imediato, em companhia de seus personagens preferidos do momento. Como destaca Roveri (2012),

O fenômeno da moda tem em Barbie sua insígnia: a boneca desperta o
gosto pelo novo e inspira o prazer de ver e de ser vista, convidando a
menina a adaptar as novidades a si e à sua coleçãa de brinquedos. O
que tem sustentado a permanência de Barbie como a boneca mais
vendida no mundo e um ícone da moda é o seu desprendimento do
passado, apoiado na lógica das mudanças de detalhes (ROVERI, 20 I2,
p. 57 . Grifos da autora).

Em 1994, ano em que Barbie completava seus 12 anos de aparição no Brasil e comemorava seus 20 milhões de itens vendidos, o vice-presidente executivo da Estrela, fábrica nacional que importou os produtos Barbie até 1997, disse em uma entrevista6 que a infinidade de acessórios que acompanham a boneca - amigos, animais, utensílios, roupas, móveis etc. - criam, durante a brincadeira, uma ambientação para que a criança exerça toda sua imaginação. Ora, esta ideia de que as crianças precisam de inúmeros produtos para que possam brincar e imaginar tem sido recorrente na mídia e ganha cada vez mais aceitação por parte das famílias e das escolas. Estas instituições, muitas vezes, preocupam-se em oferecer à criança uma gama de brinquedos e materiais acreditando com isso desenvolver o imaginário infantil. A lógica dos fabricantes não é promover a brincadeira, mas a coleção de uma série de brinquedos. Percebemos que o discurso de que Barbie traz infinitas possibilidades de brincar, podendo assumir inúmeros papéis revela, na verdade, que os empresários esperam vender mais exemplares e acessórios, como se a posse de todo sortimento fosse fator indispensável para a brincadeira.

Estratégias como a renovação do produto, as miudezas e o destaque aos detalhes operam para construir a sedução e a magia em torno do brinquedo. Ao discorrer sobre o brinquedo e a educação, Benjamin (1984), dizia que seria um equívoco acreditar que o conteúdo imaginário do brinquedo determina a brincadeira. Para ele, "quanto mais atraentes (no sentido corrente) forem os brinquedos, mais distantes estarão de seu valor como 'instrumentos' de brincar, quanto ilimitadamente a imitação anunciar-se neles, tanto mais desviam-se da brincadeira viva" (BENJAMIN, 1984, p. 60).

Quando a criança encontra espaço e tempo para entregar-se à imaginação, é capaz de deslocar-se para outros mundos, compor suas narrativas, ser autora de suas experiências. De forma oposta, a mídia trabalha com o tempo instantâneo, no qual só há possibilidade de incitar desejos, não a imaginação. Em seus estudos sobre a televisão, Bourdieu (1997), afirma que o tempo

6 A entrevista foi feita pelo jornal O Estado de São Paulo na ocasião em que a fabricante Estrela preparava um desfile de moda para comemorar o aniversário da boneca. Ver RUBERTI, Irene, 1994, p.C6. 
[...] é extremamente raro na televisão. E se minutos tão preciosos são empregados para dizer coisas tão fúteis, é que essas coisas tão fúteis são de fato muito importantes na medida em que ocultam coisas preciosas. Se insisto nesse ponto, é que se sabe, por outro lado, que há uma proporção muito importante de pessoas que não leem nenhum jornal; que estão devotadas de corpo e alma à televisão como fonte única de informações. (BOURDIEU, 1997, p.23).

A partir disso, vale ressaltar a especificidade do trabalho dos profissionais de educação: seria importante que fizessem escolhas pedagógicas conscientes, buscando propostas que contemplassem o direito ao brincar desapegado dos apelos do consumismo. Ao deixarmos de conceber a infância como o reino da inocência e da fantasia, perceberemos que a vida da criança é marcada por interesses políticos e econômicos, além de diferenças de gênero, classe, etnia, idade etc. Ora, as crianças também são produzidas historicamente pelos discursos e narrativas que se enunciam sobre elas (BUJES, 2002).

Nas reflexões a seguir, discutiremos as narrativas apresentadas pelos brinquedos e de que modo produzem um imaginário sobre os sujeitos infantis. Analisaremos, de modo especial, Barbie, uma das bonecas mais vendidas no mundo. Buscaremos, pois, desenvolver uma discussão da educação do corpo feminino por interferência deste brinquedo e suas narrativas. A história dessa boneca, seu terreno de atuação e a força da sua publicidade podem nos mostrar como nossa sociedade tem olhado para a criança, o brinquedo e o corpo.

O que Barbie quer ensinar às meninas?

Barbie foi introduzida no mercado em março de 1959, como uma modelo adolescente que tinha uma vida real. Nos comerciais de brinquedos, a Mattel foi uma das empresas pioneiras a dirigirse diretamente à criança, vislumbrando nela um grande poder de influência na família. A publicidade não deixava transparecer que Barbie era apenas uma boneca, mas sim uma personagem com caráter e estilos de vida próprios, simbolizando uma mulher elegante tal como a criança sonharia ser no futuro. As meninas eram estimuladas a convencer seus pais de que Barbie, com seu corpo de mulher adulta, conseguiria transformá-las em pequenas damas, graciosas e sedutoras. $\mathrm{O}$ argumento publicitário da Mattel induzia as mães a aceitarem o fato de que era melhor suas filhas atraírem um marido pudicamente do que permanecerem solteiras para sempre. Além disso, a criança, frente aos anúncios televisivos, receberia os argumentos necessários para dirigir-se aos adultos e solicitar-lhes os brinquedos desejados (ROVERI, 2012).

Barbie, uma boneca criada para ser o que quiser... Suas múltiplas imagens são pequenos 
fragmentos de um espelho refletor que evoca, a cada época, o consumo de uma beleza feminina idealizada. Embalada e mostrada nas lojas, a boneca é sustentada pelas mãos da menina, que com ela brinca e sonha ser estrela. Barbie foi feita para ser o espelho inquebrável que reflete um corpo alisado pelo plástico, uma barreira tão firme que a impede de desmanchar o eterno sorriso, fechar os olhos, dobrar a pele e mostrar suas marcas de mais de meio século.

Meninas criadas para serem delicadas, graciosas e obedientes recebem roupas e brinquedos em diferentes matizes de rosa, a começar pelo "rosa bebê" ao nascimento até chegar ao "pink" na adolescência. Fadas, princesas, sereias e borboletas encantadas convidam a garota a exprimir seus desejos, sonhos e sentimentos através de seu "melhor e mais sincero órgão": o coração.

Neste jogo, participam os adultos especializados em publicidade, marketing, moda, tecnologias e inúmeras áreas detentoras da produção e comercialização de brinquedos que, com suas ambições, experiências, preconceitos e interpretações da infância criam e veiculam produtos ao público infantil.

O mercado de brinquedos vende diversos modelos de acordo com um público infantil determinado e segmentado. Por exemplo, a imagem de menina dócil é direcionada para crianças pequenas e vendida através de situações de contos de fadas e princesas. A ideia da menina "popular, descolada" tem sido veiculada para crianças maiores. Empresas de brinquedos, produtos cosméticos e outras mercadorias destinam fatias de seus produtos exclusivamente às meninas adolescentes de acordo com suas interpretações sobre o que é ser mulher nesta idade. Podemos notar que a proposta de brinquedos feitos para as meninas está ligada ao embelezamento, ao brilho e às situações de compras.

As meninas, fortemente influenciadas pelos ideais de beleza evocados na publicidade, estão vulneráveis às aprovações externas, aprendem a exigir de si mesmas um sacrifício e uma crescente preocupação com a aparência. Percebemos que a infância de muitas delas é vivenciada em academias, salões de beleza, shoppings e supermercados. Como discute Soares (2011, p.67), os corpos são educados nas relações e por toda realidade que os circunda. As meninas, desde pequenas,

\footnotetext{
[...] são "educadas" a suportar essas tiranias da aparência internalizando a falta de conforto, a ausência de liberdade de movimentos, a completa falta de base de apoio para o equilíbrio do corpo causado pelos saltos altos, como sendo uma segunda natureza.
}

Barbie exerce um poder sobre o corpo das crianças, convidando-as a desfrutar de um "prestígio", através da aquisição de seus produtos e de seu modo de vida. Ora, o mercado do embelezamento infantil fragmenta o corpo da criança fazendo com que esta cultive o sentimento de insatisfação para consigo mesma, sentimento que atinge um alto índice da população feminina no 
Brasil. O corpo desejado é sempre jovem, descartável e determinado pelo mercado e que nas relações com as outras pessoas torna-se um corpo-performance, competitivo e transitório, assim como o de Barbie, que desde que fora criada, não para de mudar. Martin (2006, p.58), ao discutir o papel da ciência moderna na fragmentação da unidade da pessoa, lembra que

\section{[...] quando a ciência trata a pessoa como máquina e pressupõe que o corpo pode ser consertado por meio de manipulações mecânicas, ela ignora, e nos incentiva a ignorar, outros aspectos do nosso eu, como nossas emoções e nossas relações com as outras pessoas.}

Em mais de meio século, Barbie tem sido estampada de modo versátil, buscando atingir o maior número possível de consumidoras: negras, hispânicas e orientais, por exemplo. Mas a matriz da qual se produzem as bonecas é a de Barbie loira e branca. As "outras" bonecas são suas amigas coadjuvantes e recebem outros nomes, ou mesmo uma classificação de "étnicas" e "nativas".

Assim como uma marca que aparece carimbada sob o mesmo feitio em produtos que variam nas cores, tamanhos, sabores e formas, a etiqueta "Barbie" também é grudada em bonecas com tonalidades de pele e cabelos diferentes. De maneira geral, a indústria de brinquedos tem fabricado mercadorias personificadas que se deslocam de um estado inanimado e adquirem uma vida própria. Tais mercadorias, ao apresentarem atributos físicos reforçados pelas mídias e desejados socialmente, materializam um ideal de felicidade e anunciam variadas técnicas para compor a aparência de um corpo que quer ser notado. Como lembra Greer (2001, p.37),

\footnotetext{
A Mattel tem hoje tanto controle sobre o mercado que sua máquina de guerra pode atropelar qualquer brinquedo que ameace competir com a Barbie. A boneca tem sido um instrumento para ensinar mulheres de ombros largos, pernas curtas e corpo largo, mulheres reais em todo o mundo, a desprezar seu corpo, como de fato ocorre, para que paguem o dinheiro que se poderia investir no custo de livros, computadores ou bicicletas, por produtos "de beleza" de produção barata e embalagens caras.
}

As mulheres são educadas para a obediência às sugestões dos anúncios e de seus simulacros como estes fossem mandamentos inquestionáveis. A farsa de termos como revitalizar, rejuvenescer, nutrir, combater, recuperar, eliminar, etc., subtrai a mulher à condição vulnerável de desesperança no futuro e consequente fixação na prometida juventude eterna. Assim, as mulheres aprendem a conceber o tempo como um inimigo, pois quanto mais velhas se parecerem, menos chances terão de serem valorizadas (LOURO, 2001; SCHIEBINGER, 2001; SFEZ, 1996).

Barbie vai à escola... 
O hábito de as crianças adquirirem seus brinquedos prontos das lojas muitas vezes se sobressai à possibilidade de criação a partir de elementos que a natureza fornece: a criança também é capaz de imaginar seus brinquedos e passar longo tempo confeccionando-os com materiais desprezados ou encontrados em seu entorno. Como ressalta Finco (2003) os brinquedos são elementos culturais, portadores de significados e de um enredo social, sendo que as crianças recriam, a todo o momento, novos significados.

Quando a criança brinca com um pedaço de pau, com uma caixa de papelão, sucatas e com outros materiais que não necessariamente são brinquedos, desenvolve a imaginação e a criação por meio da brincadeira. O brincar não necessariamente pressupõe um objeto, como sugerem as cantigas de roda, por exemplo. Oliveira (1986) e Barthes (1982) discutem que a prática de consumir um brinquedo industrializado fez com que as crianças perdessem o hábito de passar grande tempo construindo seus próprios objetos a partir da transformação dos elementos encontrados na natureza. A indústria utiliza cada vez mais produtos sintéticos pois estes correspondem financeiramente a seus propósitos, ao contrário de elementos naturais outrora usados, como a madeira e inúmeras fibras. Feitos de materiais cada vez mais sintéticos, os brinquedos deixam à criança poucas opções de intervenção em seu formato, limitando experiências sensoriais como a do toque, do cheiro e do som, por exemplo.

A indústria estampa, através do plástico, miniaturas de objetos os quais os adultos decidiram ser os mais rentáveis e apropriados para meninos e meninas brincarem. O brinquedo atual é feito para ser utilizado por um curto período e trocado rapidamente por outro de uma nova coleção. A lógica da remoção e do descarte desvaloriza a durabilidade de um produto, promovendo o impulso de comprar e substituir tudo o que é considerado obsoleto. Os veículos de comunicação propagam que "novas necessidades exigem novas mercadorias, que por sua vez exigem novas necessidades e novos desejos; o advento do consumismo augura uma era de "obsolescência embutida" dos bens oferecidos no mercado e assinala um aumento espetacular na indústria da remoção do lixo" (BAUMAN, 2008, p. 45).

No que cabe aos profissionais da educação, podemos dizer que seria importante repensarem a organização dos espaços para brincadeiras e para as relações, permitindo que a criança faça descobertas, invenções, imagine e construa, superando os limites classificatórios que os brinquedos industrializados muitas vezes trazem. Não se trata de negar e coibir a brincadeira com brinquedos como Barbie e outros industrializados, mas sim ampliar o repertório das crianças, mostrando-lhes outras referências, outras possibilidades de ser e de agir que superem aquelas que os brinquedos sugerem. Admitimos assim, conforme propõe Almeida (2006, p. 550), que 
[...] ao perceber-se na criança o verdadeiro ator social de suas ações, um ser ativo dotado de sentido de competência na sociedade em que vive, espera-se construir um novo sentido de valorização da experiência da infância, longe da visão idealizada do adulto que, ao olhar para trás, contempla sua própria infância.

Ao propor que a escola reflita sobre a educação por meio das imagens e dos sons, Almeida (2004, p.7), discute que "quando se fala de cinema, vídeo e televisão na escola, geralmente encaram-se essas produções como ilustrações - o professor passa um filme para ilustrar o que foi falado”. Nas instituições de educação infantil, por exemplo, muitos filmes são escolhidos com o propósito de “divertir e entreter", substituindo a linguagem oral-escrita, que é lida e escutada, por aquela que é vista.

Nos filmes de Barbie, a boneca é apresentada em papéis de princesa, borboleta, fada, sereia e bailarina; suas atitudes estão ligadas ao coração, visto como o lugar próprio da expressão dos sentimentos femininos. A publicidade veicula a ideia de que os sentimentos das meninas devem ser sinceros e puros para que os sonhos se realizem: "Barbie em A Princesa da Ilha - Uma aventura musical mostra que, quando somos guiados pelo amor, milagres podem estar mais próximos do que imaginamos"”. A cada filme lançado, Barbie sempre renova seus acessórios, disponibilizando nas lojas os adereços e personagens supérfluos que fizeram parte do enredo de suas histórias.

Assim, a concepção de feminilidade focada no coração é apresentada por Barbie em todos os seus desenhos, nos quais é possível ouvir frases como "O destino está escrito nas estrelas", "amor e imaginação podem mudar o mundo" e "deixo o meu coração me guiar". Já para os meninos a mesma fabricante tem dito, através de sua linha de carrinhos, frases como "você detonou!", "esmague tudo o que vier pela frente!", “vire de cabeça para baixo”, "devore o maior número de carrinhos que puder antes de o tempo acabar", "alcance uma super velocidade nesta pista irada!" e "um looping animal que vai causar várias batidas!"8

Ao discutir o cotidiano das instituições de educação infantil, Kishimoto (1998), observa que tem desaparecido a produção de objetos que refletem a riqueza do mundo cultural e natural de nosso país, brinquedos que aumentam o repertório imaginativo da criança e brincadeiras diversas - além de contos e lendas - que destacam a pluralidade cultural brasileira e que forneçam conteúdo à expressão imaginativa da criança'.

A valorização das brincadeiras coletivas seria um compromisso da escola com o brincar, já

\footnotetext{
7 Parte da sinopse do filme: Barbie em a Princesa da llha, Universal Pictures, 2007.

8 Frases como estas podem ser encontradas no site de jogos e brinquedos "para meninos" da Mattel: <http://umw.hotwheels.com/pt-br/index.html>. Acesso em 20 maio 2013.

9 Sobre este aspecto, destacamos também o projeto "Território do Brincar", no qual uma intensa pesquisa coordenada por Renata Meirelles nos apresenta as sutilezas e as nuances das brincadeiras das crianças brasileiras. Disponível em: <http://mww.territoriodobrincar.com.br>. Acesso 27mar. 2013.
} 
que, muitas vezes, o espaço público não promove o encontro das pessoas. Nos grandes centros urbanos, a rua e os parques são lugares vistos como perigosos e as crianças, por vezes, brincam sozinhas com os brinquedos dos quais são as proprietárias. A escola, nesse sentido, é um dos espaços privilegiados para diversos tipos de criações e de brincadeiras coletivas.

\section{Conclusão}

A discussão que aqui nos propusemos a fazer acerca do brinquedo, em especial a boneca Barbie, ajuda a perceber que a infância é marcada por relações sócio-culturais, políticas e econômicas (KUHLMANN Jr., 1998). As crianças são alvos de consumo de instituições comerciais e inúmeras fontes de entretenimento. $\mathrm{O}$ brinquedo, longe de ser inocentemente concebido, é uma mercadoria que interfere na construção de uma cultura infantil. As pegadas deixadas pelas corporações no percurso realizado para atrair as crianças ao consumo apontam para o desejo, o prazer, a culpa e a ansiedade (STEINBERG e KINCHELOE, 2001).

Ao elegermos a boneca Barbie para discutirmos a infância, procuramos refletir sobre os padrões de comportamento e de corpo ensinados às crianças em nossa sociedade. A boneca, além de instigar a menina a comprar seu mundo para que nele seja feliz, é também um espelho que a convida a restaurar o corpo tal qual a anatomia de plástico que se glorifica nos meios de comunicação. Os brinquedos e outros artigos de consumo trazem, em geral, indicativos de feminilidade e de masculinidade, condicionando comportamentos ao estilo do produto. Inúmeras mercadorias são dirigidas às crianças de modo a lhes sugerir distinção social; meninas e meninos estão defrontes a um universo de consumo em que ídolos e estrelas são criados para coordenar o fluir da moda, estimulando o desejo dos prazeres e das performances que eles simulam ter (COUTO, 1998; ROVERI, 2012).

De fato, Barbie não tem se importado se a criança brinca com ela ou não, seu principal interesse é fazer da menina uma colecionadora de cada produto novo lançado no mercado e fixar seu emblema cor de rosa na vida das crianças. Permitir que a criança brinque, invente, sinta, explore, remexa, teste possibilidades e costure suas fantasias, ao invés de meramente consumir, é um grande 
ALMEIDA, D.B.L. de. Sobre brinquedos e infância: aspectos da experiência e da cultura do brincar. Educ. Soc., Campinas, vol. 27, n. 95, p. 541-551, maio/ago. 2006, p.541-551.

ALMEIDA, M. J. de. Imagens e sons: a nova cultura oral. São Paulo: Cortez, 2004.

BARTHES, Roland. Mitologias. São Paulo: Difel, 1982.

BAUMAN, Z. Vida para consumo: a transformação das pessoas em mercadoria. Rio de Janeiro: Zahar, 2008.

BENJAMIN, W. Reflexões: a criança, o brinquedo, a educação. São Paulo: Summus, 1984.

BOURDIEU, P. Sobre a televisão: seguido de a influência do jornalismo e os Jogos Olímpicos. Rio de Janeiro: Zahar, 1997.

BUJES, M. I. E. Infância e maquinarias. Rio de Janeiro: DP\&A, 2002.

COUTO, E. S. O Homem-Satélite: Estética e Mutações do Corpo na Sociedade Tecnológica. Ijuí: Unijuí, 2000.

FINCO, D. Relações de gênero nas brincadeiras de meninos e meninas na educação infantil. ProPosições, v.14, n.3(42) set./dez.2003. p. 89-101.

GREER, G. A mulher inteira. Rio de Janeiro: Record, 2001.

KISHIMOTO, T. M. Escolarização e brincadeira na educação infantil. In: SOUSA, C. P. de (org). História da Educação: processos, práticas e saberes. São Paulo: Escrituras Editora, 1998, p.123136.

KLEIN, N. Sem logo: A tirania das marcas em um planeta vendido. São Paulo: Record, 2006.

KUHLMANN Jr., Moysés. Infância e educação infantil: uma abordagem histórica. Porto Alegre: Mediação, 1998.

LOURO, G. L. (org.). O corpo educado: pedagogias da sexualidade. Belo Horizonte: Autêntica, 2001.

MARTIN, E. A mulher no corpo: Uma análise cultural da reprodução. Rio de Janeiro: Garamond, 2006.

OLIVEIRA, P. de S. Brinquedo e indústria cultural. Petrópolis: Vozes, 1986

ROVERI, F. T. Barbie na educação de meninas: do rosa ao choque. São Paulo: Annablume, 2012.

RUBERTI, Irene. Gente grande faz festa pelos 35 anos da Barbie. O Estado de São Paulo, p. C6, 29 jun. 1994.

SCHIEBINGER, L. O feminismo mudou a ciência? Bauru: EDUSC, 2001.

SFEZ, L. A saúde Perfeita: crítica de uma nova utopia. São Paulo: Unimarco; Loyola, 1996.

SIBILIA, P. O homem pós-orgânico: corpo, subjetividade e tecnologias digitais. Rio de Janeiro: Relume Dumará, 2002.

SOARES, C. L. As roupas nas práticas corporais e esportivas: A educação do corpo entre o conforto, a elegância e a eficiência (1920-1940). Campinas, SP: Autores Associados, 2011. 
STEINBERG, S.R. e KINCHELOE, J. L. (orgs). Cultura Infantil: A construção corporativa da Infância. Rio de Janeiro: Civilização Brasileira, 2001. 